\title{
Characterization and bioactivities of the exopolysaccharide from a probiotic strain of Lactobacillus plantarum WLPL04
}

\author{
Zhengqi Liu, ${ }^{*}$ Zhihong Zhang, ${ }^{*}$ Liang Qiu,† Fen Zhang,‡ Xiongpeng Xu, ${ }^{*}$ Hua Wei, ${ }^{*}$ and Xueying Tao*1 \\ *State Key Laboratory of Food Science and Technology, Nanchang University, Nanchang 330047, China \\ †School of Life Sciences, Jiangxi University of Traditional Chinese Medicine, Nanchang, 330004, China \\ $\ddagger$ School of Life Sciences, Nanchang University, Nanchang 330031, China
}

\section{ABSTRACT}

Exopolysaccharide (EPS) was extracted and purified from Lactobacillus plantarum WLPL04, which has been confirmed previously as a potential probiotic for its antagonistic and immune-modulating activity. It has a molecular weight of $6.61 \times 10^{4} \mathrm{Da}$, consisting of xylose, glucose, and galactose in an approximate molar ratio of 3.4:1.8:1. Microstructural studies demonstrated that the EPS appeared as a smooth sheet structure with many homogeneous rod-shaped lumps. The preliminary in vitro assays indicated that the EPS could significantly inhibit the adhesion of Escherichia coli O157:H7 to HT-29 cells in competition, replacement, and inhibition assays at a dose of $1.0 \mathrm{mg} / \mathrm{mL}$, with an inhibition rate of $20.24 \pm 2.23,29.71 \pm 1.21$, and $30.57 \pm 1.73 \%$, respectively. Additionally, the EPS exhibited strong inhibition against biofilm formation by pathogenic bacteria, including Pseudomonas aeruginosa CMCC10104, E. coli O157:H7, Salmonella Typhimurium ATCC13311, and Staphylococcus aureus CMCC26003. Furthermore, the EPS showed good inhibitory activity against the proliferation of HT-29 cells. The characteristics and bioactivities of this EPS may make it a promising candidate in developing functional food.

Key words: Lactobacillus plantarum WLPL04, exopolysaccharide, characterization, bioactivities

\section{INTRODUCTION}

Exopolysaccharides (EPS) represent a large group of biopolymers that are produced during the metabolic process of microorganisms (Amjres et al., 2015) and can be classified as homo- or heteropolysaccharides, according to whether they are composed of one or more types of sugar. Among the variety of EPS-producing microorganisms, lactic acid bacteria (LAB) have been

Received August 31, 2016.

Accepted May 11, 2017.

${ }^{1}$ Corresponding author: 1027txy@163.com recognized as having safe status, and have attracted more attention due to their potential probiotic properties (Badel et al., 2011).

The EPS produced by LAB have received a great deal of interest in the fermented food industry (Liu et al., 2010; Serafini et al., 2013) because they are used as natural additives of in situ fermentation to promote physicochemical properties, such as stabilizing, emulsifying, and providing texture and mouthfeel of cheese, yogurt, and so on (Badel et al., 2011; Patel et al., 2012; Ahmed et al., 2013). In addition to applications in the dairy industry, EPS of LAB have several potential applications due to their biological activities [e.g., antioxidant activity (Li et al., 2014a), antitumor activity (Wang et al., 2014), activity against biofilm forming by pathogens (Li et al., 2014b, 2015), cholesterol-lowering activity (London et al., 2014), and immunomodulation (Wu et al., 2010; Li and Shah, 2014)]. Furthermore, EPS have been shown to be important for LAB because of potential roles in stress resistance, adhesion, colonization, and host-bacteria interactions (Fanning et al., 2012; Dertli et al., 2013; Lee et al., 2016).

Recently, Lactobacillus plantarum has attracted scientific interest due to its broad distribution in ecological niches (pickles, sausage, sourdough, and so on), beneficial effects on the host, and high commercial value for dairy products (da Silva Sabo et al., 2014; Kwak et al., 2014). The EPS-producing L. plantarum strains were considered beneficial microorganisms and widely used as starters for various fermented dairy products (da Silva Sabo et al., 2014; Kwak et al., 2014; Caggianiello et al., 2016), and the structures and bioactivities of EPS have been disclosed in some publications ( $\mathrm{Li}$ et al., 2013; Fontana et al., 2015; Zhou et al., 2016). However, the molecular weight $(\mathbf{M w})$ and monosaccharide composition are strain dependent, and so are the biological functions (e.g., antioxidant, antitumor, and antibiofilm activity).

In our previous study, an EPS-producing L. plantarum WLPL04 from human breast milk has been found with antibacterial and antiinflammatory ability, and it exhibited antiadhesion capability against pathogens 
to the human intestinal epithelial cells (Jiang et al., 2016). Its genome data have also been reported (Tao et al., 2015). The objectives of the present work were to isolate and purify the EPS from L. plantarum WLPL04 and determine its molecular and monosaccharide composition using gel-permeation chromatography (GPC) and GC-MS, respectively. We also investigated the physicochemical properties of EPS using UV-visible spectrophotometry, Fourier-transform infrared (FTIR) spectroscopy, scanning electron microscopy, and atomic force microscopy (AFM). Furthermore, the probiotic properties of EPS were evaluated in vitro, including antiadhesion activity, activity against biofilm formation by pathogens, and its antitumor activities.

Due to the increasing incidence of colon cancer and the side effects of current chemical antitumor drugs, developing natural antitumor compounds is becoming critically important to prevent colon cancer (Zhang et al., 2012). Our work provided a pre-fundamental basis for reasonable use of EPS for human health.

\section{MATERIALS AND METHODS}

\section{Bacterial Growth, Cell Culture, and Culture Conditions}

The EPS-producing strain L. plantarum WLPL04 was previously isolated from healthy female breast milk (Jiang et al., 2016), and cultured in de Man, Rogosa, and Sharpe broth (Beijing Solarbio Science and Technology Co. Ltd., Beijing, China) at $37^{\circ} \mathrm{C}$ under anaerobic condition. Indicator strains of pathogens

(Pseudomonas aeruginosa CMCC10104, Escherichia coli O157:H7, Salmonella Typhimurium ATCC13311, and Staphylococcus aureus CMCC26003) were cultured in Luria-Bertani medium at $37^{\circ} \mathrm{C}$ overnight in a shaker incubator.

Human colon cancer HT-29 cells, purchased from Cell Bank of the Chinese Academy of Sciences (Beijing, China), were cultured in Dulbecco's modified Eagle's medium supplemented with 10\% (vol/vol) heatinactivated fetal bovine serum (ExCell Bio Co., Ltd., Shanghai, China) and a standard mixture of antibiotics (100 U/mL of penicillin, $100 \mu \mathrm{g} / \mathrm{mL}$ of streptomycin; Beijing Solarbio Science and Technology Co. Ltd.) in an atmosphere of $5 \%(\mathrm{vol} / \mathrm{vol}) \mathrm{CO}_{2}$ at $37^{\circ} \mathrm{C}$, in $75-\mathrm{cm}^{2}$ cell culture flasks, and the medium was replaced every $2 \mathrm{~d}$.

\section{EPS Isolation and Purification}

The EPS was isolated and purified as described previously (Zhang et al., 2016). Briefly, after incubation at $37^{\circ} \mathrm{C}$ for $24 \mathrm{~h}$, culture of L. plantarum WLPL04 was centrifuged at $9,000 \times g$ for $5 \mathrm{~min}$ at $4^{\circ} \mathrm{C}$ to remove the bacteria; then, 2 volumes of chilled absolute ethyl alcohol were added. The solution was centrifuged at 10,000 $\times g$ for $20 \mathrm{~min}$ at $4^{\circ} \mathrm{C}$. The precipitates were collected and dissolved in Milli-Q water (Millipore, Shanghai, China) to dialyze against Milli-Q water for $3 \mathrm{~d}$ at $4^{\circ} \mathrm{C}$, which was changed twice a day. Crude EPS was obtained by lyophilizing, and then additionally purified to reduce the DNA and protein content. Briefly, the crude EPS powder was dissolved in $50 \mathrm{~m} M$ Tris- $\mathrm{HCl}, 10 \mathrm{mM}$ $\mathrm{MgSO}_{4} \cdot 7 \mathrm{H}_{2} \mathrm{O}(\mathrm{pH} 7.5)$ at a final concentration of $5 \mathrm{mg} /$ $\mathrm{mL}$ and treated with DNase I (final concentration 2.5 $\mu \mathrm{g} / \mathrm{mL}$, Sigma, St. Louis, MO) at $37^{\circ} \mathrm{C}$ for $6 \mathrm{~h}$, followed by Pronase E (final concentration $50 \mu \mathrm{g} / \mathrm{mL}$, Sigma) treatment at $37^{\circ} \mathrm{C}$ for $18 \mathrm{~h}$. Afterward, trichloroacetic acid was added ( $12 \%$ final concentration) to precipitate enzymes and residual AA or peptides, and the mixture was stirred for $30 \mathrm{~min}$ at room temperature. The solution was centrifuged at $10,000 \times g$ for $20 \mathrm{~min}$ at $4^{\circ} \mathrm{C}$ to collect supernatant, which was adjusted to $\mathrm{pH} 4.0$ to 5.0 with $10 \mathrm{M} \mathrm{NaOH}$. After dialysis at $4^{\circ} \mathrm{C}$ for $3 \mathrm{~d}$ against Milli-Q water (water was changed twice daily), the dialyzed retentate was finally freeze-dried to obtain pure EPS powder for subsequent experiments.

The EPS was suspended in distilled water $(1 \mathrm{mg} / \mathrm{L})$ and the concentration was determined by the phenolsulfuric acid method (DuBois et al., 1956) using glucose as standard, and the purity of EPS was analyzed by a UV-visible spectrophotometer (TU-1901, Persee, China) in the wavelength range of 200 to $600 \mathrm{~nm}$.

\section{Molecular Weight Analysis of EPS}

The Mw of the purified EPS was determined by GPC equipped with a TSK G-5000 PWXL column $(7.8 \times 300$ mm, TOSOH, Tokyo, Japan) and TSK G-3000 PWXL column $(7.8 \times 300 \mathrm{~mm}$, TOSOH $)$ in conjunction with a refractive index detector (Waters 2414, Milford, MA). The samples $(2.0 \mathrm{mg} / \mathrm{mL}, 20 \mu \mathrm{L})$ were injected and eluted with $0.02 \mathrm{~mol} / \mathrm{L} \mathrm{KH}_{2} \mathrm{PO}_{4}$ solutions at $35^{\circ} \mathrm{C}$ with a flow rate of $0.6 \mathrm{~mL} / \mathrm{min}$. Data were collected and processed using Breeze 1 GPC software (Waters). Molecular weights were calculated according to the relative molecular mass of dextran standards (Sigma).

\section{Determination of Monosaccharide Composition of EPS}

A total of $5 \mathrm{mg}$ of the purified EPS was hydrolyzed with $2 \mathrm{~mL}$ of $2.0 \mathrm{M}$ trifluoroacetic acid at $100^{\circ} \mathrm{C}$ for $30 \mathrm{~min}$. The hydrolysates were then repeatedly coconcentrated with methanol to dryness, and converted to their trimethylsilyl derivatives by adding $0.2 \mathrm{~mL}$ of trimethylchlorosilane, $0.4 \mathrm{~mL}$ of hexam-ethyldisilazane, 
$1 \mathrm{~mL}$ of pyridine, and heating at $80^{\circ} \mathrm{C}$ for $30 \mathrm{~min}$. After cooling, samples were analyzed on HP 7890A GC (Agilent, Santa Clara, CA) equipped with a flame-ionization detector and a HP-5 fused-silica capillary column (30 $\mathrm{m} \times 0.32 \mathrm{~mm} \times 0.25 \mathrm{~mm}, \mathrm{~J} \& \mathrm{~W}$ Scientific Inc., Folsom, CA). The chromatographic conditions were set according to our previous method (Zhang et al., 2016). Rhamnose, arabinose, fucose, xylose, mannose, glucose, and galactose were prepared for comparison and inositol was used as an internal standard.

\section{FT-IR Spectroscopy Analysis}

Fourier-transform infrared spectroscopy was used to detect the major structural groups of the purified EPS. The sample of EPS was pressed in $\mathrm{KBr}$ pellet and recorded on a FT-IR spectrophotometer (FTIR Nicolet 5700, Thermo Nicolet Co., Waltham, MA) in the region from 400 to $4,000 \mathrm{~cm}^{-1}$.

\section{Microscopic Morphology Analysis of EPS}

The microscopic morphology of the purified EPS was evaluated by scanning electron microscopy and AFM. The purified EPS was fixed to the scanning electron microscopy stubs with double-sided tape and then coated with a layer of gold approximately $10 \mathrm{~nm}$ thick. The samples were observed in a scanning electron microscope (JSM 6701F, Jeol, Tokyo, Japan) at an acceleration voltage of $3.0 \mathrm{kV}$.

The purified EPS was dissolved in distilled $\mathrm{H}_{2} \mathrm{O}$ at the concentration of $1 \mathrm{mg} / \mathrm{mL}$. The aqueous solution was stirred for $2 \mathrm{~h}$ at $40^{\circ} \mathrm{C}$ in a sealed bottle under a stream of $\mathrm{N}_{2}$ until the EPS dissolved completely. After cooling to room temperature, the solution was diluted to a final concentration of $10 \mu \mathrm{g} / \mathrm{mL}$. Five-microliter solutions were dropped onto the surface of a mica sample carrier and allowed to dry at room temperature. Then the AFM images were obtained by PicoView program in the tapping mode (Agilent 5500).

\section{Effects on Adhesion of E. coli 0157:H7 to HT-29 Cells}

The effects of the purified EPS on adhesion of E. coli O157:H7 to HT-29 cells were evaluated as reported by Donnarumma et al. (2014). Briefly, HT-29 cells were incubated in 6 -well plates $\left(5.0 \times 10^{5}\right.$ cells per well $)$ under $5 \% \mathrm{CO}_{2}$ at $37^{\circ} \mathrm{C}$ for $24 \mathrm{~h}$. Then, $100 \mu \mathrm{L}$ of $\mathrm{E}$. coli O157:H7 $\left(1 \times 10^{8} \mathrm{cfu} / \mathrm{mL}\right)$ and $10 \mu \mathrm{L}$ of EPS with different concentrations $(0.01,0.1$, and $1.0 \mathrm{mg} / \mathrm{mL})$ were added for 3 types of assays: (1) competition assay (i.e., adding EPS and E. coli simultaneously and incubated for $1 \mathrm{~h}$ ); (2) displacement assay (i.e., pre-incubating
HT-29 cells with $100 \mu \mathrm{L}$ of $E$. coli for 1 h, then adding EPS and incubating for another $1 \mathrm{~h}$ ); and (3) inhibition assay (i.e., pre-incubating HT-29 cells with EPS for $1,4,6$, and $18 \mathrm{~h}$, then adding $100 \mu \mathrm{L}$ of $E$. coli and incubating for another $1 \mathrm{~h}$ ). After incubation, unbound bacteria were washed off and adhered bacteria were detached by EDTA-trypsin solution (Sigma). The attached $E$. coli cells were counted by plating on LuriaBertani agar. The ability of EPS to inhibit the adhesion of $E$. coli to HT-29 cells was expressed as the percentage of adhesion of $E$. coli added with EPS relative to the one without EPS (control).

\section{Anti-Biofilm Activity}

The inhibition assay of biofilm formation was carried out as described by Li et al. (2014b) with a slight modification. Overnight cultivated pathogens were diluted to $1.0 \times 10^{8} \mathrm{cfu} / \mathrm{mL}$ and added into a 96-well plate together with aqueous solution of EPS of different concentration $(0.2,0.5,1.0,2.0$, and $5.0 \mathrm{mg} / \mathrm{mL})$, which was sterilized by filtration through a $0.22-\mu \mathrm{m}$ membrane filter. Wells without EPS were used as a negative control, and wells adding ampicillin $(50 \mu \mathrm{g} /$ $\mathrm{mL}$ ) as a positive control. After $24 \mathrm{~h}$ incubation at $37^{\circ} \mathrm{C}$, the wells were washed with PBS and dried under the room temperature. The biofilms were stained with $2 \%$ (wt/vol) crystal violet (Tianjin Kemiou Chemical Reagent Co., Tianjin, China). Then, the dye was solubilized with $0.16 \mathrm{~mL}$ of $33 \%$ (vol/vol) glacial acetic acid. To determine the biofilm mass, aliquots of $125 \mu \mathrm{L}$ of the solubilized dye from each well were transferred into a new 96-well plate and the absorbance at $590 \mathrm{~nm}$ was measured by a microplate reader (DNM-9602, Perlong Medical Co., Beijing, China). The antibiofilm ability was calculated using the following formula: antibiofilm activity $(\%)=\left[1-\left(\mathrm{OD}_{\text {sample }} / \mathrm{OD}_{\text {negative control }}\right)\right] \times 100$, where OD is optical density.

\section{Antitumor Activity}

The antitumor activity of the purified EPS on HT-29 cells was evaluated by a 3 -(4, 5-dimethylthiazol-2-yl)-2, 5-diphenyltetrazolium bromide (MTT) assay as previously reported (Wang et al., 2015b) with slight modification. Briefly, HT-29 cells were incubated in 96-well plates $\left(2.0 \times 10^{4}\right.$ cells/well $)$ under $5 \% \mathrm{CO}_{2}$ at $37^{\circ} \mathrm{C}$ for $24 \mathrm{~h}$. The cells were then treated with $100 \mu \mathrm{L}$ of the various concentrations of $\operatorname{EPS}(50,100,200,400$, and $800 \mu \mathrm{g} / \mathrm{mL}$ ) and fluorouracil (5-FU, $50 \mu \mathrm{g} / \mathrm{mL}$ ) for 24, 48, and $72 \mathrm{~h}$. After incubation, $10 \mu \mathrm{L}$ of MTT (5.0 $\mathrm{mg} / \mathrm{mL}$ ) was added into each well, and the cells were incubated for another $4 \mathrm{~h}$. Then, the supernatant was discarded, and $100 \mu \mathrm{L}$ of dimethyl sulfoxide was added 


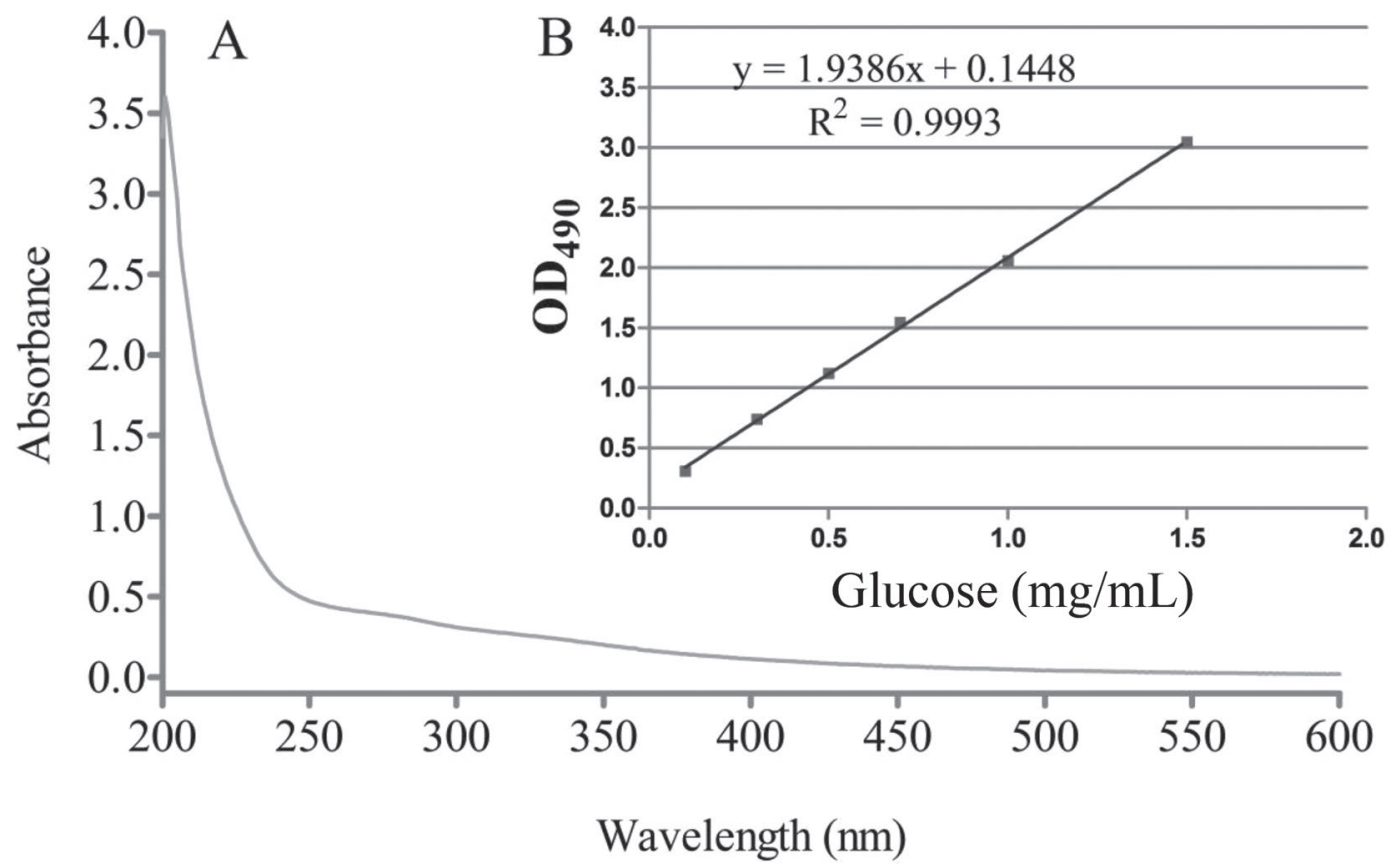

Figure 1. The UV spectrum of the purified exopolysaccharide from Lactobacillus plantarum WLPL04 in the range of 200 to $600 \mathrm{~nm}$ (A), and the calibration curve of glucose used for the phenol-sulfuric acid method (B). $\mathrm{OD}_{490}=$ optical density at $490 \mathrm{~nm}$.

to solubilize the formazan. The absorbance at 570 $\mathrm{nm}$ of the plate was measured by a microplate reader (DNM-9602, Perlong Medical Co., Beijing, China). The inhibition rate was calculated as follows: inhibition rate $(\%)=\left[1-\left(\mathrm{OD}_{\text {sample }}-\mathrm{OD}_{\text {blank }}\right) /\left(\mathrm{OD}_{\text {control }}-\mathrm{OD}_{\text {blank }}\right)\right]$ $\times 100$, where $\mathrm{OD}_{\text {control }}$ and $\mathrm{OD}_{\text {blank }}$ were the absorbance with and without the addition of the EPS and cells, respectively.

\section{Statistical Analysis}

Triplicate data were expressed as mean $\pm \mathrm{SD}$. The SPSS 13.0 software (SPSS Inc., Chicago, IL) was used to perform statistical analyses by means of independent 1-way ANOVA tests. Differences with $P<0.05$ were considered statistically significant.

\section{RESULTS AND DISCUSSION}

\section{Purification of the EPS}

The crude EPS, obtained from the supernatant of L. plantarum WLPL04, was shown to have a nonropy phenotype by ethanol precipitation. DNase I and Pronase $\mathrm{E}$ were used to remove DNA and protein of the crude EPS. After lyophilizing, some light brown powder was obtained, which could be dissolved into water with a transparency state (data not shown). Our previous study showed that the EPS yielding of $L$. plantarum
WLPL04 reached the highest amount of $426.73 \pm 65.56$ $\mathrm{mg} / \mathrm{L}$ at $24 \mathrm{~h}$ (Jiang et al., 2016); in this study, the purity of the EPS was proved to be $96.48 \%$ as determined by phenol-sulfuric acid method (Figure 1B).

The UV-visible spectrum of purity EPS showed no absorption at 260 or $280 \mathrm{~nm}$, indicating that the purified EPS was free from protein and nucleic acid (Figure $1 \mathrm{~A})$.

\section{Molecular Weight of EPS}

Molecular weight is a basic property of EPS that might influence the probiotic properties ( $\mathrm{Xu}$ et al., 2010). In this study, the Mw of the EPS was analyzed by GPC. The chromatogram of the EPS appeared as a symmetrical narrow peak at 25.55 min (data not shown), with an elution volume of $15.33 \mathrm{~mL}$. According to the calibration curve of standards $[\log \mathrm{Mw}=$ $-0.351 \mathrm{~V}_{\mathrm{E}}+10.109, \mathrm{R}^{2}=0.9918$; where $\mathrm{V}_{\mathrm{E}}$ is the elution volume $(\mathrm{mL})]$, the $\mathrm{Mw}$ of the EPS from L. plantarum WLPL04 was determined to be $6.61 \times 10^{4} \mathrm{Da}$, which was lower than that of the EPS $\left(1.1 \times 10^{5} \mathrm{Da}\right)$ from L. plantarum YW11 (Wang et al., 2015a) and the EPS $\left(1.15 \times 10^{6} \mathrm{Da}\right)$ of L. plantarum C88 (Zhang et al., 2013), but higher than that $\left(1.83 \times 10^{4}\right.$ and $1.33 \times$ $10^{4} \mathrm{Da}$ ) of the EPS of L. plantarum BC-25 (Zhou et al., 2016). In our parallel study, the $\mathrm{Mw}$ of L. plantarum ZDY2013 was $5.17 \times 10^{4}$ Da by high-performance size exclusion chromatography (Zhang et al., 2016). 


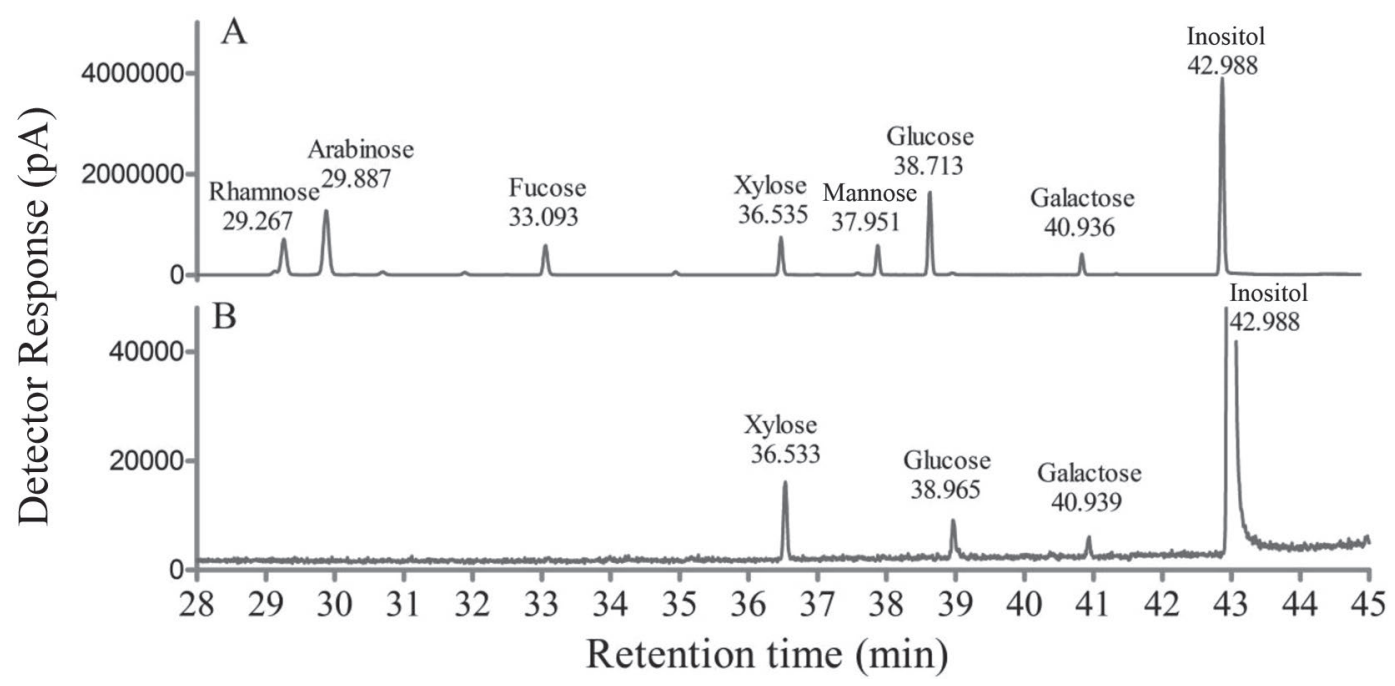

Figure 2. Gas chromatograms of standard sugars (A) and purified exopolysaccharide of Lactobacillus plantarum WLPL04 (B). The retention times correspond to rhamnose (29.267), arabinose (29.887), fucose (33.093), xylose (36.535), mannose (37.951), glucose (38.713), galactose (40.936), and inositol (42.988).

The $\mathrm{Mw}$ of EPS produced by L. plantarum strain is important for understanding its bioactivity and potential structure-function relationship of the EPS in fermented milk (Vaningelgem et al., 2004). A high-Mw EPS could improve the texture of fermented milk and may have greater antitumor activity than low-Mw EPS (Hassan et al., 2003; Peng et al., 2005). Moreover, the differences in Mw of EPS might be associated with its specific functions.

\section{Monosaccharide Composition of EPS}

Gas chromatography-mass spectrometry was used to analyze the monosaccharide composition of the EPS from WLPL04. As shown in Figure 2, the EPS was composed of xylose, glucose, and galactose in a molar ratio of 3.4:1.8:1 (Figure 2B), determined by comparing the retention time with the standards (Figure 2A), and xylose was the predominant monosaccharide in the EPS. As previously reported, most EPS produced by other L. plantarum strains consists of galactose and glucose (Zhang et al., 2013; Wang et al., 2015a), and additional $\mathrm{N}$-acetylgalactosamine (Tallon et al., 2003) or mannose (Ismail and Nampoothiri, 2010; Wang et al., 2010; Zhou et al., 2016). Specially, the EPS produced by L. plantarum NTU102 contained arabinose, galactose, glucose, fructose, mannose, and maltose (Liu et al., 2011). Only the EPS produced by L. plantarum ZDY2013 contained xylose, but at a very low ratio $(1.7 \%$ of total monosaccharide; Zhang et al., 2016). These results suggested that the monosaccharide composition of EPS differs among strains, and this composition might be closely related to the varied functions of EPS (Bello et al., 2001; Russo et al., 2012; Das et al., 2014), which was in accordance with some previous research (Wang et al., 2014; Caggianiello et al., 2016).

\section{FT-IR Spectrum Analysis of EPS}

To investigate the functional groups of the purified EPS, an FT-IR spectrum was recorded at the absorbance mode from 4,000 to $500 \mathrm{~cm}^{-1}$. As shown in Figure 3 , the spectrum of the purified EPS of WLPL04 showed an intense and broad band at around $3,417 \mathrm{~cm}^{-1}$, which was considered the $\mathrm{O}-\mathrm{H}$ stretching vibration (Wang et al., 2010). The strong absorbance peak around 2,931 $\mathrm{cm}^{-1}$ was assigned to $\mathrm{C}-\mathrm{H}$ stretching vibration ( $\mathrm{Li}$ et al., 2014b). The band around $1,645 \mathrm{~cm}^{-1}$ was due to the stretching vibration of $\mathrm{C}=\mathrm{O}$ and carboxyl group (Wang et al., 2015a). Two peaks were observed around 1,413 and $1,249 \mathrm{~cm}^{-1}$, which were assigned to $\mathrm{C}-\mathrm{O}$ stretching vibrations and $\mathrm{O}-\mathrm{H}$ deformation vibrations (Wang et al., 2012). The bands in the region of 900 to 1,150 $\mathrm{cm}^{-1}$ were attributed to the vibration of $\mathrm{C}-\mathrm{O}-\mathrm{C}$ bond (Wang et al., 2015a). Generally, the FT-IR spectrum of L. plantarum WLPL04 was similar to L. plantarum ZDY2013, as described in our previous report (Zhang et al., 2016).

\section{Microcosmic Morphology of EPS}

The microstructure and surface morphology of the purified EPS from L. plantarum WLPL04 were observed by scanning electron microscopy (Figure 4), which showed an irregular structure resembling sheets of polysaccharide overlaid with some scattered pieces 
(Figure 4A) and that appeared as a smooth surface under 5,000× magnification (Figure 4B), exhibiting sheet and compact structure. A previous study suggested that this smooth surface is a favorable characteristic of the material used to make plasticized biofilms (Wang et al., 2010), and the consistent polymeric matrix of EPS gives mechanical stability to biofilms (Saravanan and Shetty, 2016).

Recently, EPS has been extensively studied by AFM, which is a powerful tool to observe the morphological topographies of polymers. The AFM images of the EPS from WLPL04 are shown in Figures 4C and 4D. The EPS deposited from a $10 \mu \mathrm{g} / \mathrm{mL}$ aqueous solution exhibited many homogeneous rod-shaped lumps with height ranging from 0.25 to $4.51 \mathrm{~nm}$, which was significantly greater than that of a single polysaccharide chain (approximately $0.1-1 \mathrm{~nm}$ ). This structural property of the EPS was also observed in Bifidobacterium animalis $\mathrm{RH}$, and might be involved with inter- or intramolecular aggregation (or both) of polysaccharide chains and branches, and further forming of the interconnecting network structure (Shang et al., 2013).

\section{Effect of the EPS on Adhesion of E. coli 0157:H7 to HT-29 Cells}

The antiadhesion ability against pathogens is considered one of the most important assays when evaluating probiotic properties. In our previous study, L. planta-

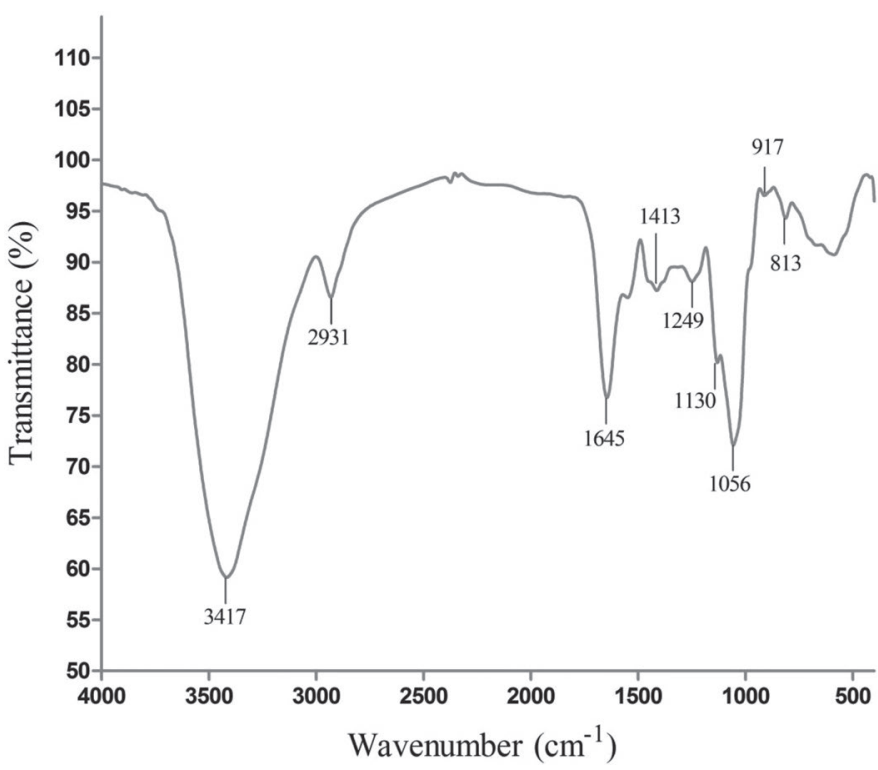

Figure 3. Fourier-transform infrared spectrum of the purified exopolysaccharide from Lactobacillus plantarum WLPL04 in the range of 400 to $4,000 \mathrm{~cm}^{-1}$. rum WLPL04 has shown a significant inhibitory effect on adhesion of E. coli O157:H7 to human intestinal epithelial cells (Jiang et al., 2016). To investigate whether the EPS of WLPL04 had a similar inhibitory effect on adhesion, we assessed the adhesion of E. coli O157:H7 to HT-29 cells in the presence of EPS by competition, displacement, and inhibition assays.

As shown in Figure 5, EPS was able to compete with, displace, and inhibit $E$. coli $\mathrm{O} 157: \mathrm{H} 7$ at different levels and the effects were concentration dependent. In competition and displacement assays (Figures 5A and $5 \mathrm{~B})$, the inhibition ratio dramatically increased with the concentration of EPS (0.01 to $1.0 \mathrm{mg} / \mathrm{mL}$ ), with maximal inhibition rates of $20.24 \pm 2.23 \%$ and 29.71 $\pm 1.21 \%$, respectively. In the inhibition assay (Figure 5C), when HT-29 cells were pre-incubated for a long period $(18 \mathrm{~h})$ with a low concentration of EPS (0.01 $\mathrm{mg} / \mathrm{mL}$ ), the inhibition rate significantly increased up to $21.55 \pm 1.89 \%$; however, at the high concentration of EPS $(1.0 \mathrm{mg} / \mathrm{mL})$, inhibition rates were not correlated with incubation time, and the highest rate was $31.91 \pm$ $1.87 \%$ at $6 \mathrm{~h}$.

According to our previous study, we further proved that not only the viable cells of L. plantarum WLPL04 but also its EPS reduced the adhesion of $E$. coli O157:H7 by competition, displacement, and inhibition assays. To our knowledge, few studies have focused on the antiadhesion effect of EPS from lactobacilli strains against pathogens. Donnarumma et al. (2014) used the EPS of $L$. crispatus L1 to reduce the adhesion of Candida albicans to Vk2/E6E7 cells by inhibition assay $(1.0 \mathrm{mg} / \mathrm{mL}$ of EPS, pre-incubated for $18 \mathrm{~h})$, with an inhibition rate of $48 \%$.

\section{Inhibition of Pathogens to Form Biofilm}

Except for the antiadhesion effect against pathogens in vitro, probiotics and their metabolic substances (e.g., EPS) face a challenge of in vivo formation of biofilm by pathogens, which is quite critical for their resistance to antibiotics and the host immune system as a result of persistent chronic infections (Jiang et al., 2011). We investigated activity against biofilm formation of the purified EPS from strain WLPL04 to pathogens and the result is shown in Figure 6. The inhibitory effects of the purified EPS $(0.2,0.5,1.0,2.0$, and $5.0 \mathrm{mg} / \mathrm{mL})$ on 4 pathogens (i.e., P. aeruginosa CMCC10104, E. coli O157:H7, Salmonella Typhimurium ATCC13311, and $S$. aureus CMCC26003) increased gradually with increasing concentrations of EPS (0.2 to $5.0 \mathrm{mg} / \mathrm{mL}$ ), without a significant difference $(P<0.05)$, and the highest inhibition was for P. aeruginosa CMCC10104 (47.02 \pm $4.83 \%)$ and lowest for E. coli O157:H7 (25.82 $\pm 5.34 \%)$. 
When compared with the positive group of ampicillin $(50 \mu \mathrm{g} / \mathrm{mL})$, the difference of the effect of inhibition by EPS was nonsignificant at higher concentrations $(2.0,5.0 \mathrm{mg} / \mathrm{mL})$. Previous studies reported that EPS from L. helveticus MB2-1 also showed activity against biofilm formation by pathogens, with inhibition rates of $43.58 \%$ (against P. aeruginosa PAO1), $65.82 \%$ ( $S$. aureus ATCC 6538), and $33.41 \%$ (E. coli K-12; Li et al., 2014b); EPS of L. plantarum YW32 showed inhibition rates of $45.13 \%$ ( $S$. aureus AC1), $44.04 \%$ (Salmonella Typhimurium S50333), and $12.71 \%$ (E. coli O157:H7; Wang et al., 2015b). These results demonstrated that strains of L. plantarum from different resources might have different specificity against pathogens (GarciaRuiz et al., 2014).

Plenty of literature has reported the inhibition of pathogens by LAB, mainly focusing on the effect of organic acids (e.g., lactic acid and acetic acid); a few studies have mentioned the antagonism of EPS from L. plantarum against pathogens. Our results showed that EPS of WLPL04 had a broad activity againt those biofilm-forming pathogens. Biofilm formation is a problem not only for chronic infection by pathogen in the host, but also for the disinfection procedures
A

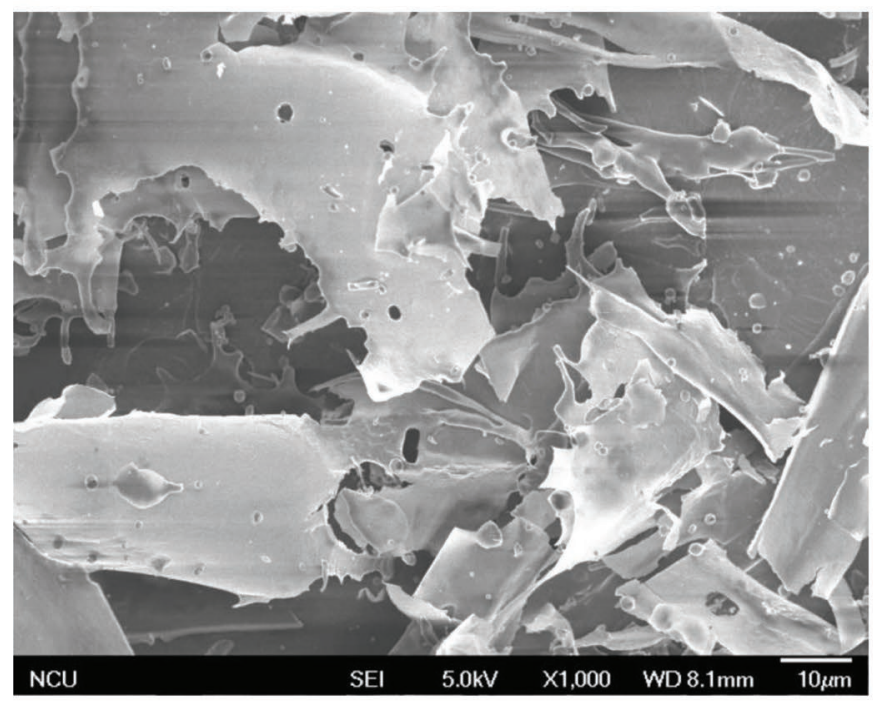

B

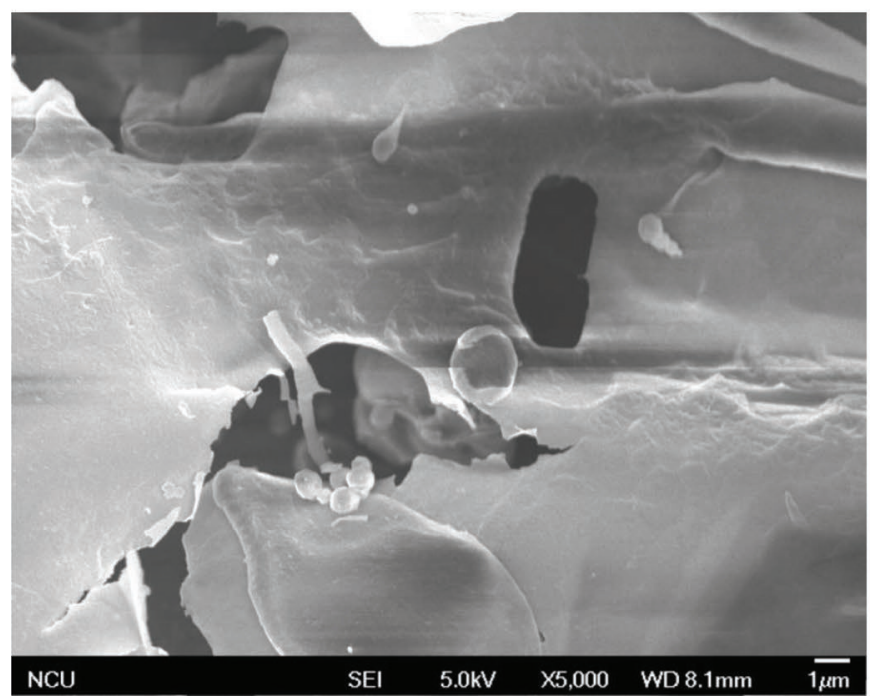

C

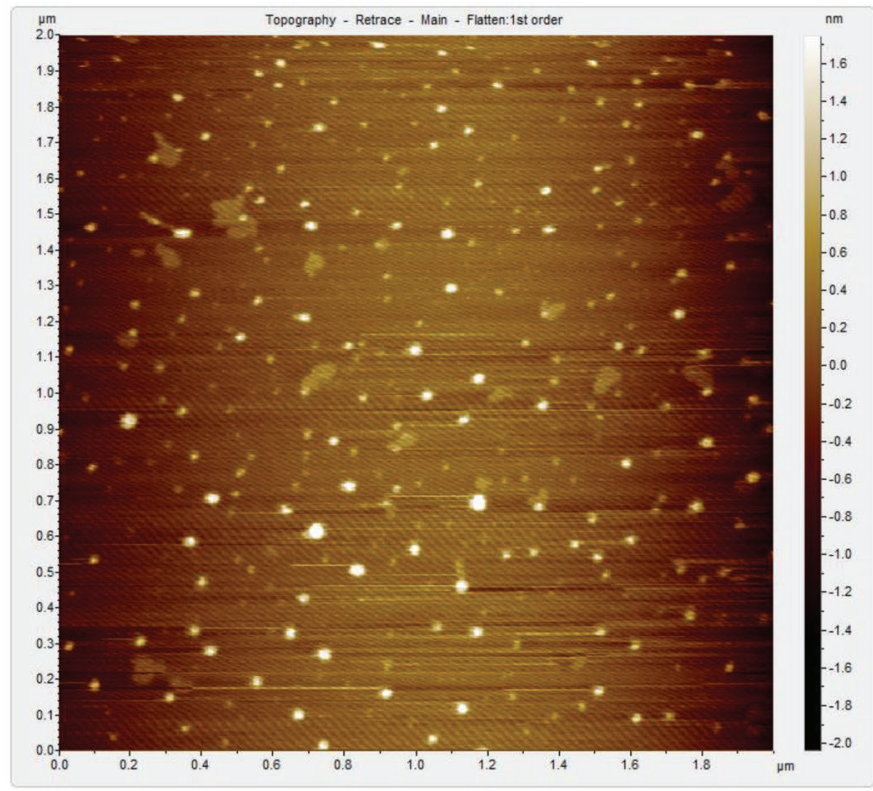

D

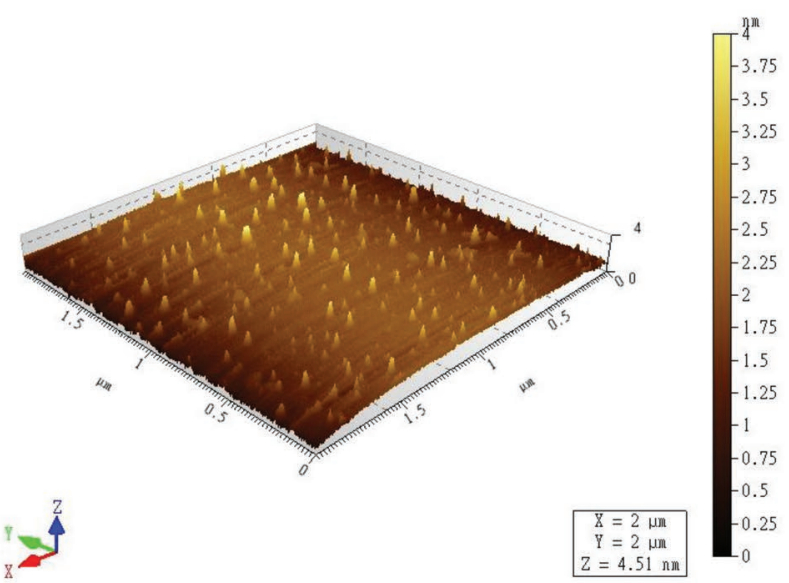

Figure 4. Scanning electron micrograph images of the purified exopolysaccharide (EPS) from Lactobacillus plantarum WLPL04 (A: 1,000×, B: $5,000 \times)$. Planar (C) and cubic (D) atomic force microscopy images of the purified EPS from L. plantarum WLPL04. Color version available online. 

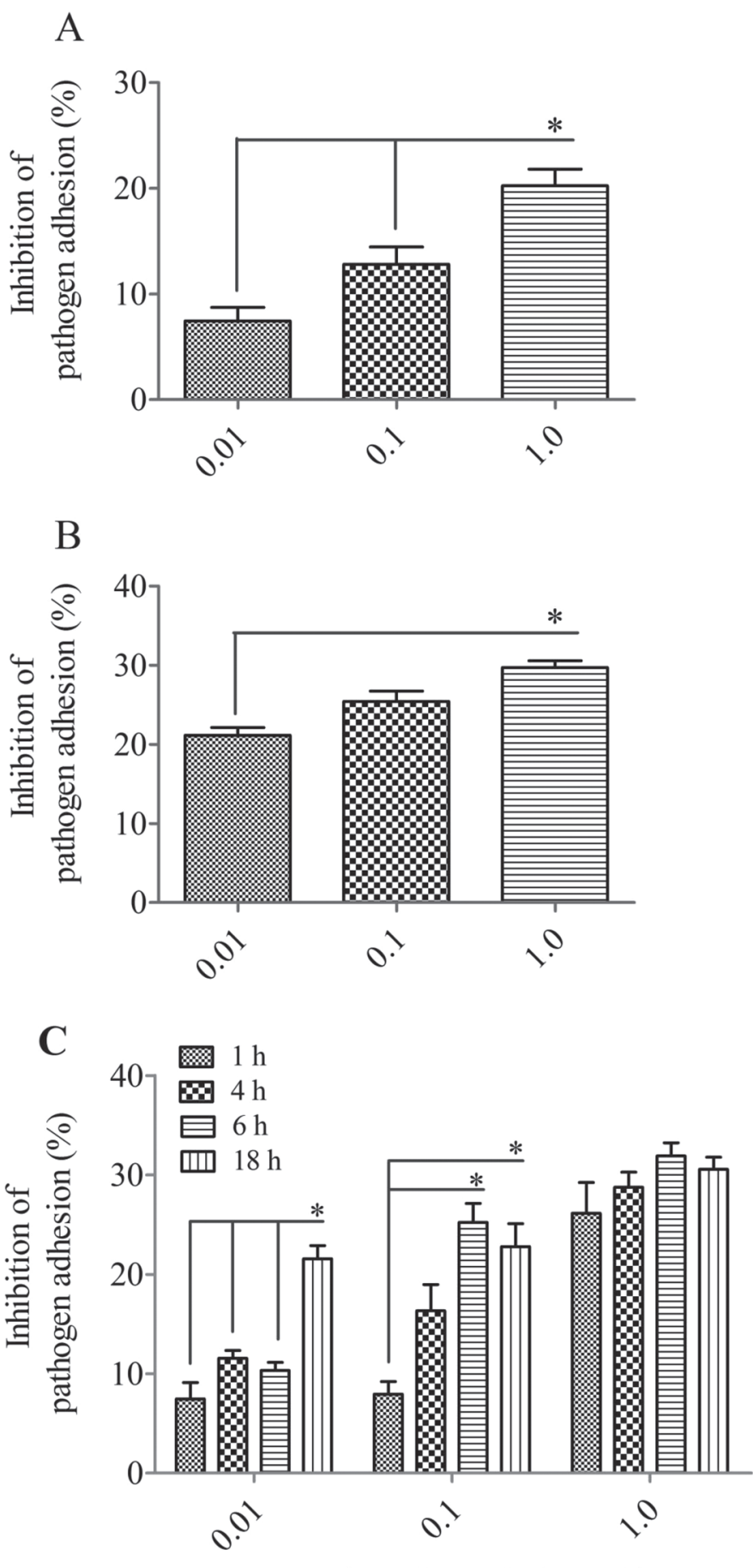

Concentration of sample $(\mathrm{mg} / \mathrm{mL})$

Figure 5. Antiadhesion assays (A: competition, B: displacement, and C: inhibition) of Escherichia coli O157:H7 on human colon cancer HT-29 cells in the presence of exopolysaccharide (EPS; 0.01, 0.1, and $1.0 \mathrm{mg} / \mathrm{mL}$ ) from Lactobacillus plantarum WLPL04. The inhibition rate was calculated as the relative reduction percentage of the test group (EPS), using the control group (without EPS) as 100\% of adhesion. Data of triplicate trials were expressed as the mean $\pm \mathrm{SD}$. ${ }^{*} P$ $<0.05$. in food processing. Although we did not evaluate the mechanism of activity against biofilm formation by the EPS in our study, this effect occurs by inhibiting of the initial attachment of the bacterial cell surface (Valle et al., 2006), by influencing the release of substances associated with biofilm formation (Wu et al., 2016), or by modifying the bacterial cell surfaces (Rendueles et al., 2013).

\section{Antitumor Activity}

The EPS from WLPL04 was not only antagonistic against the adhesion of pathogens and formation of biofilm, but it might have antitumor activity. The antitumor activity of EPS at different concentrations $(50,100,200,400$, and $800 \mu \mathrm{g} / \mathrm{mL})$ was investigated by using 5 -FU $(50 \mu \mathrm{g} / \mathrm{mL})$ as a positive control. As shown in Figure 7, EPS had a nonsignificant difference on antitumor activity compared with 5-FU. The antitumor effect of EPS increased with time and concentration. After incubation for $72 \mathrm{~h}$ at $800 \mu \mathrm{g} / \mathrm{mL}$ of EPS, the inhibition rate was the highest $(60.77 \pm 11.11 \%)$. Wang et al. (2014) reported that the inhibition rate of EPS $(600 \mu \mathrm{g} / \mathrm{mL})$ from L. plantarum 70810 was $88.34 \%$, when treated for $72 \mathrm{~h}$, whereas Wang et al. (2015b) showed that the inhibition rate of EPS from L. plantarum YW32 was $39.24 \%$ under the same conditions. The reasons for the difference may be due to the different $\mathrm{Mw}$, monosaccharide composition, and grouped structure of different EPS (Wu et al., 2014).

\section{CONCLUSIONS}

In this study, EPS from L. plantarum WLPL04 was isolated, purified, and shown to have a molecular mass of $6.61 \times 10^{4} \mathrm{Da}$. The EPS was composed of xylose, glucose, and galactose in an approximate molar ratio of 3.4:1.8:1. Under the microscope, purified EPS showed a smooth sheet structure with many homogeneous rodshaped lumps. The purified EPS exhibited excellent capacity to inhibit the adhesion of $E$. coli $\mathrm{O} 157: \mathrm{H} 7$ to HT-29 cells, and had probiotic properties such as activity against biofilm formation by several pathogenic bacteria, and antitumor activity against HT-29 cells. These results showed that EPS from L. plantarum WLPL04 has obvious biological activities in vitro, which might form the basis for potential application of EPS from $L$. plantarum WLPL04 in developing functional food.

\section{ACKNOWLEDGMENTS}

This work was financed by National Natural Science Foundation of China (31260363 and 31360377), Ganpo 


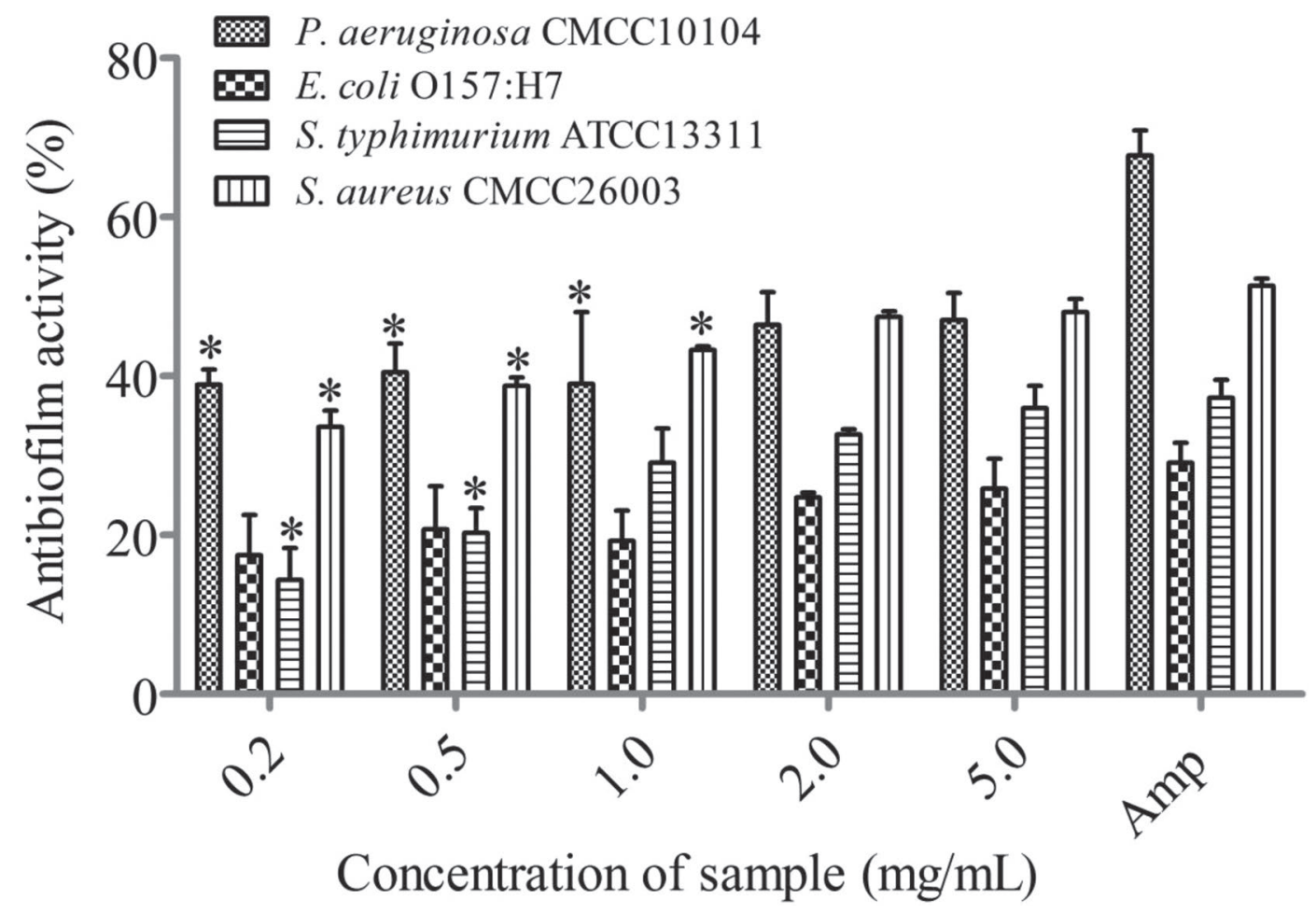

Figure 6. Anti-biofilm-formation assays of the purified exopolysaccharide (EPS; 0.2, 0.5, 1.0, 2.0, and $5.0 \mathrm{mg} / \mathrm{mL}$ ) from Lactobacillus plantarum WLPL04 against Pseudomonas aeruginosa CMCC10104, Escherichia coli O157:H7, Salmonella Typhimurium ATCC13311, and Staphylococcus aureus CMCC26003. Ampicillin (Amp; $50 \mu \mathrm{g} / \mathrm{mL}$ ) was used as a reference material. Data are presented as the mean \pm SD of triplicates. ${ }^{*} P<0.05$.

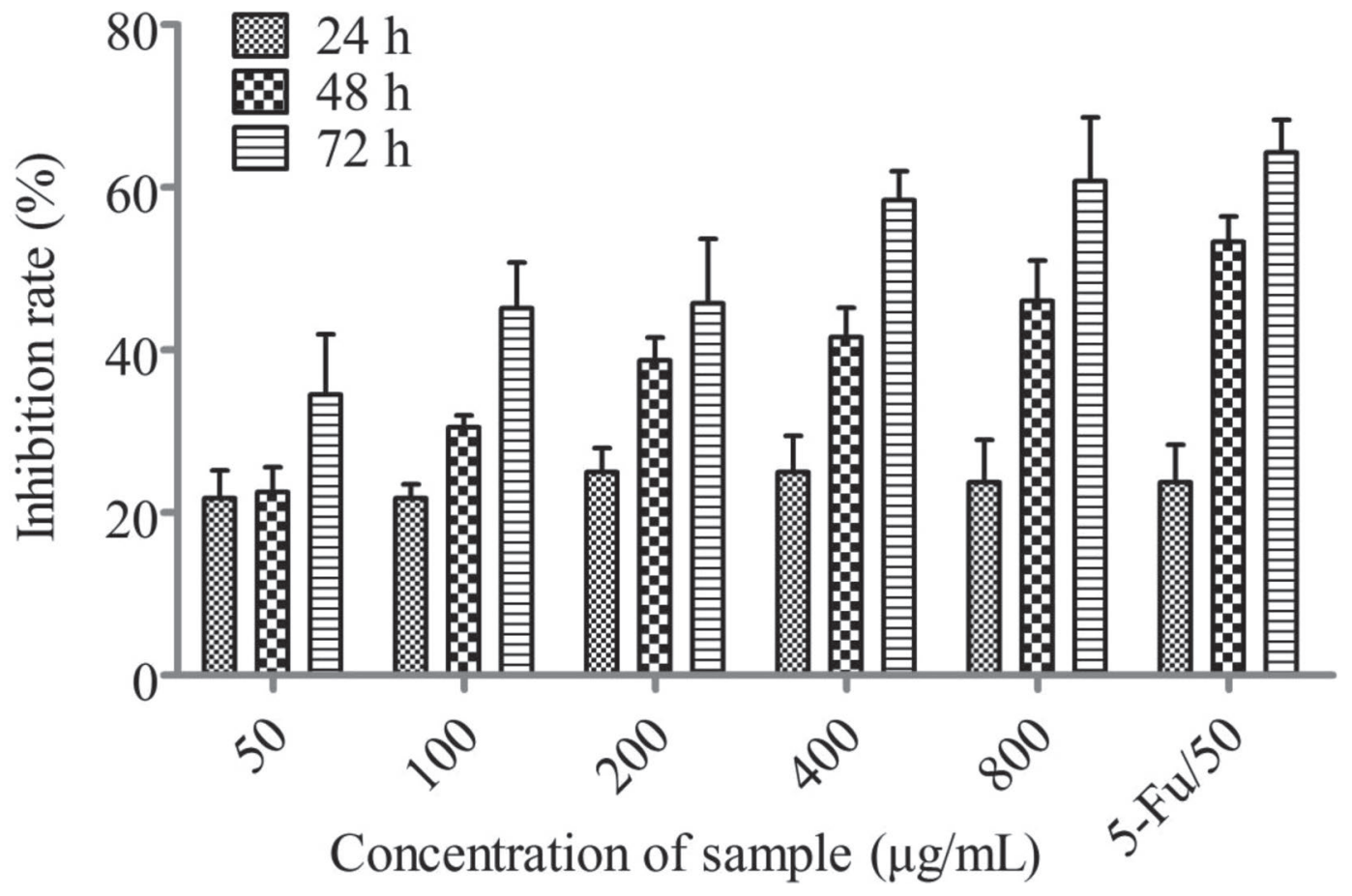

Figure 7. In vitro inhibitory assay of the purified exopolysaccharide from Lactobacillus plantarum WLPL04 at different concentrations (50, 100, 200, 400, and $800 \mu \mathrm{g} / \mathrm{mL})$ against human colon cancer HT-29 cells in 24, 48, and $72 \mathrm{~h}$; fluorouracil $(5-\mathrm{Fu} ; 50 \mu \mathrm{g} / \mathrm{mL})$ was used as a reference. Data are presented as the mean $\pm \mathrm{SD}$ of triplicates. 
Talent 555 Engineering Project of Jiangxi Province (2013, China).

\section{REFERENCES}

Ahmed, Z., Y. Wang, N. Anjum, A. Ahmad, and S. T. Khan. 2013. Characterization of exopolysaccharide produced by Lactobacillus kefiranofaciens ZW3 isolated from Tibet kefir - Part II. Food Hydrocoll. 30:343-350.

Amjres, H., V. Bejar, E. Quesada, D. Carranza, J. Abrini, C. Sinquin J. Ratiskol, S. Colliec-Jouault, and I. Llamas. 2015. Characterization of haloglycan, an exopolysaccharide produced by Halomonas stenophila HK30. Int. J. Biol. Macromol. 72:117-124.

Badel, S., T. Bernardi, and P. Michaud. 2011. New perspectives for Lactobacilli exopolysaccharides. Biotechnol. Adv. 29:54-66.

Bello, F. D., J. Walter, C. Hertel, and W. P. Hammes. 2001. In vitro study of prebiotic properties of levan-type exopolysaccharides from Lactobacilli and non-digestible carbohydrates using denaturing gradient gel electrophoresis. Syst. Appl. Microbiol. 24:232-237.

Caggianiello, G., M. Kleerebezem, and G. Spano. 2016. Exopolysaccharides produced by lactic acid bacteria: From health-promoting benefits to stress tolerance mechanisms. Appl. Microbiol. Biotechnol. 100:3877-3886.

da Silva Sabo, S., M. Vitolo, J. M. D. González, and R. P. de Souza Oliveira. 2014. Overview of Lactobacillus plantarum as a promising bacteriocin producer among lactic acid bacteria. Food Res. Int. 64:527-536.

Das, D., R. Baruah, and A. Goyal. 2014. A food additive with prebiotic properties of an alpha-D-glucan from Lactobacillus plantarum DM5. Int. J. Biol. Macromol. 69:20-26.

Dertli, E., I. J. Colquhoun, A. P. Gunning, R. J. Bongaerts, G. Le Gall, B. B. Bonev, M. J. Mayer, and A. Narbad. 2013. Structure and biosynthesis of two exopolysaccharides produced by Lactobacillus johnsonii FI9785. J. Biol. Chem. 288:31938-31951.

Donnarumma, G., A. Molinaro, D. Cimini, C. De Castro, V. Valli, V. De Gregorio, M. De Rosa, and C. Schiraldi. 2014. Lactobacillus crispatus L1: High cell density cultivation and exopolysaccharide structure characterization to highlight potentially beneficial effects against vaginal pathogens. BMC Microbiol. 14:137.

DuBois, M., K. A. Gilles, J. K. Hamilton, P. T. Rebers, and F. Smith. 1956. Colorimetric method for determination of sugars and related substances. Anal. Chem. 28:350-356.

Fanning, S., L. J. Hall, M. Cronin, A. Zomer, J. MacSharry, D. Goulding, M. O. C. Motherway, F. Shanahan, K. Nally, and G. Dougan. 2012. Bifidobacterial surface-exopolysaccharide facilitates commensal-host interaction through immune modulation and pathogen protection. Proc. Natl. Acad. Sci. USA 109:2108-2113.

Fontana, C., S. Y. Li, Z. N. Yang, and G. Widmalm. 2015. Structural studies of the exopolysaccharide from Lactobacillus plantarum C88 using NMR spectroscopy and the program CASPER. Carbohydr. Res. 402:87-94.

Garcia-Ruiz, A., D. Gonzalez de Llano, A. Esteban-Fernandez, T. Requena, B. Bartolome, and M. V. Moreno-Arribas. 2014. Assessment of probiotic properties in lactic acid bacteria isolated from wine. Food Microbiol. 44:220-225.

Hassan, A. N., R. Ipsen, T. Janzen, and K. B. Qvist. 2003. Microstructure and rheology of yogurt made with cultures differing only in their ability to produce exopolysaccharides. J. Dairy Sci. $86: 1632-1638$

Ismail, B., and K. M. Nampoothiri. 2010. Production, purification and structural characterization of an exopolysaccharide produced by a probiotic Lactobacillus plantarum MTCC 9510. Arch. Microbiol. 192:1049-1057.

Jiang, M., F. Zhang, C. Wan, Y. Xiong, N. P. Shah, H. Wei, and X. Tao. 2016. Evaluation of probiotic properties of Lactobacillus plantarum WLPL04 isolated from human breast milk. J. Dairy Sci. 99:1736-1746.

Jiang, P., J. Li, F. Han, G. Duan, X. Lu, Y. Gu, and W. Yu. 2011. Antibiofilm activity of an exopolysaccharide from marine bacterium Vibrio sp. QY101. PLoS One 6:e18514.
Kwak, S.-H., Y.-M. Cho, G.-M. Noh, and A.-S. Om. 2014. Cancer preventive potential of kimchi lactic acid bacteria (Weissella cibaria, Lactobacillus plantarum). J. Cancer Prev. 19:253-258.

Lee, I. C., G. Caggianiello, and S. van Swam., IITaverne, N., M. Meijerink, P. A. Bron, G. Spano, and M. Kleerebezem. 2016. Strainspecific features of extracellular polysaccharides and their impact on Lactobacillus plantarum-host interactions. Appl. Environ. Microbiol. 82:3959-3970.

Li, J. Y., M. M. Jin, J. Meng, S. M. Gao, and R. R. Lu. 2013. Exopolysaccharide from Lactobacillus planterum LP6: Antioxidation and the effect on oxidative stress. Carbohydr. Polym. 98:1147-1152.

Li, S., R. Huang, N. P. Shah, X. Tao, Y. Xiong, and H. Wei. 2014a. Antioxidant and antibacterial activities of exopolysaccharides from Bifidobacterium bifidum WBIN03 and Lactobacillus plantarum R315. J. Dairy Sci. 97:7334-7343.

Li, S., and N. P. Shah. 2014. Antioxidant and antibacterial activities of sulphated polysaccharides from Pleurotus eryngii and Streptococcus thermophilus ASCC 1275. Food Chem. 165:262-270.

Li, W., J. Ji, X. Rui, J. Yu, W. Tang, X. Chen, M. Jiang, and M. Dong. 2014b. Production of exopolysaccharides by Lactobacillus helveticus MB2-1 and its functional characteristics in vitro. Lebensm. Wiss. Technol. 59:732-739.

Li, Y., Q. Li, D. Hao, D. Jiang, Y. Luo, Y. Liu, and Z. Zhao. 2015. Production, purification, and antibiofilm activity of a novel exopolysaccharide from Arthrobacter sp. B4. Prep. Biochem. Biotechnol. 45:192-204.

Liu, C., J. Lu, L. Lu, Y. Liu, F. Wang, and M. Xiao. 2010. Isolation, structural characterization and immunological activity of an exopolysaccharide produced by Bacillus licheniformis 8-37-0-1. Bioresour. Technol. 101:5528-5533.

Liu, C. F., K. C. Tseng, S. S. Chiang, B. H. Lee, W. H. Hsu, and T. M. Pan. 2011. Immunomodulatory and antioxidant potential of $\mathrm{Lac}$ tobacillus exopolysaccharides. J. Sci. Food Agric. 91:2284-2291.

London, L. E., A. H. Kumar, R. Wall, P. G. Casey, O. O'Sullivan, F. Shanahan, C. Hill, P. D. Cotter, G. F. Fitzgerald, R. P. Ross, N. M. Caplice, and C. Stanton. 2014. Exopolysaccharide-producing probiotic Lactobacilli reduce serum cholesterol and modify enteric microbiota in ApoE-deficient mice. J. Nutr. 144:1956-1962.

Patel, S., A. Majumder, and A. Goyal. 2012. Potentials of exopolysaccharides from lactic acid bacteria. Indian J. Microbiol. 52:3-12.

Peng, Y., L. Zhang, F. Zeng, and J. F. Kennedy. 2005. Structure and antitumor activities of the water-soluble polysaccharides from Ganoderma tsugae mycelium. Carbohydr. Polym. 59:385-392.

Rendueles, O., J. B. Kaplan, and J. M. Ghigo. 2013. Antibiofilm polysaccharides. Environ. Microbiol. 15:334-346.

Russo, P., P. Lopez, V. Capozzi, P. F. de Palencia, M. T. Duenas, G. Spano, and D. Fiocco. 2012. Beta-glucans improve growth, viability and colonization of probiotic microorganisms. Int. J. Mol. Sci. 13:6026-6039.

Saravanan, C., and P. K. Shetty. 2016. Isolation and characterization of exopolysaccharide from Leuconostoc lactis KC117496 isolated from idli batter. Int. J. Biol. Macromol. 90:100-106.

Serafini, F., F. Strati, P. Ruas-Madiedo, F. Turroni, E. Foroni, S. Duranti, F. Milano, A. Perotti, A. Viappiani, S. Guglielmetti, A. Buschini, A. Margolles, D. van Sinderen, and M. Ventura. 2013. Evaluation of adhesion properties and antibacterial activities of the infant gut commensal Bifidobacterium bifidum PRL2010. Anaerobe 21:9-17.

Shang, N., R. Xu, and P. Li. 2013. Structure characterization of an exopolysaccharide produced by Bifidobacterium animalis RH. Carbohydr. Polym. 91:128-134

Tallon, R., P. Bressollier, and M. C. Urdaci. 2003. Isolation and characterization of two exopolysaccharides produced by Lactobacillus plantarum EP56. Res. Microbiol. 154:705-712.

Tao, X., M. Jiang, F. Zhang, F. Xu, and H. Wei. 2015. Draft genome sequence of Lactobacillus plantarum WLPL04, isolated from human breast milk. Genome Announc. 3:e01443-e15.

Valle, J., S. Da Re, N. Henry, T. Fontaine, D. Balestrino, P. LatourLambert, and J. M. Ghigo. 2006. Broad-spectrum biofilm inhibition by a secreted bacterial polysaccharide. Proc. Natl. Acad. Sci USA 103:12558-12563. 
Vaningelgem, F., M. Zamfir, F. Mozzi, T. Adriany, M. Vancanneyt, J. Swings, and L. De Vuyst. 2004. Biodiversity of exopolysaccharides produced by Streptococcus thermophilus strains is reflected in their production and their molecular and functional characteristics. Appl. Environ. Microbiol. 70:900-912.

Wang, J., X. Zhao, Z. Tian, Y. Yang, and Z. Yang. 2015a. Characterization of an exopolysaccharide produced by Lactobacillus plantarum YW11 isolated from Tibet kefir. Carbohydr. Polym. $125: 16-25$.

Wang, J., X. Zhao, Y. Yang, A. Zhao, and Z. Yang. 2015b. Characterization and bioactivities of an exopolysaccharide produced by $L a c$ tobacillus plantarum YW32. Int. J. Biol. Macromol. 74:119-126.

Wang, K., W. Li, X. Rui, X. Chen, M. Jiang, and M. Dong. 2014. Characterization of a novel exopolysaccharide with antitumor activity from Lactobacillus plantarum 70810. Int. J. Biol. Macromol. 63:133-139.

Wang, Y., C. Li, P. Liu, Z. Ahmed, P. Xiao, and X. Bai. 2010. Physical characterization of exopolysaccharide produced by Lactobacillus plantarum KF5 isolated from Tibet kefir. Carbohydr. Polym. 82:895-903.

Wang, Y., F. Mao, and X. Wei. 2012. Characterization and antioxidant activities of polysaccharides from leaves, flowers and seeds of green tea. Carbohydr. Polym. 88:146-153.

Wu, M. H., T. M. Pan, Y. J. Wu, S. J. Chang, M. S. Chang, and C. Y. Hu. 2010. Exopolysaccharide activities from probiotic bifidobacterium: Immunomodulatory effects (on J774A.1 macrophages) and antimicrobial properties. Int. J. Food Microbiol. 144:104-110.
Wu, S., G. Liu, W. Jin, P. Xiu, and C. Sun. 2016. Antibiofilm and antiinfection of a marine bacterial exopolysaccharide against Pseudomonas aeruginosa. Front. Microbiol. 7:102.

Wu, Z., J. Lu, X. Wang, B. Hu, H. Ye, J. Fan, M. Abid, and X. Zeng. 2014. Optimization for production of exopolysaccharides with antitumor activity in vitro from Paecilomyces hepiali. Carbohydr. Polym. 99:226-234.

Xu, R., Q. Shen, X. Ding, W. Gao, and P. Li. 2010. Chemical characterization and antioxidant activity of an exopolysaccharide fraction isolated from Bifidobacterium animalis RH. Eur. Food Res. Technol. 232:231-240.

Zhang, D., H. Wu, Z. Xia, C. Wang, J. Cai, Z. Huang, L. Du, P. Sun, and J. Xie. 2012. Partial characterization, antioxidant and antitumor activities of three sulfated polysaccharides purified from Bullacta exarata. J. Funct. Foods 4:784-792.

Zhang, L., C. Liu, D. Li, Y. Zhao, X. Zhang, X. Zeng, Z. Yang, and S. Li. 2013. Antioxidant activity of an exopolysaccharide isolated from Lactobacillus plantarum C88. Int. J. Biol. Macromol. 54:270275

Zhang, Z., Z. Liu, X. Tao, and H. Wei. 2016. Characterization and sulfated modification of an exopolysaccharide from Lactobacillus plantarum ZDY2013 and its biological activities. Carbohydr. Polym. 153:25-33.

Zhou, K., Y. Zeng, M. Yang, S. Chen, L. He, X. Ao, L. Zou, and S. Liu. 2016. Production, purification and structural study of an exopolysaccharide from Lactobacillus plantarum BC-25. Carbohydr. Polym. 144:205-214. 